Article

\title{
Synthesis of $\mathrm{ZnAl}_{2} \mathrm{O}_{4}$ and Evaluation of the Response in Propane Atmospheres of Pellets and Thick Films Manufactured with Powders of the Oxide
}

\author{
Emilio Huízar-Padilla ${ }^{1}\left(\mathbb{D}\right.$, Héctor Guillén-Bonilla ${ }^{2, *} \mathbb{D}$, Alex Guillén-Bonilla ${ }^{3}(\mathbb{D}$, \\ Verónica-María Rodríguez-Betancourtt ${ }^{4}$, A. Sánchez-Martínez ${ }^{5}$, José Trinidad Guillen-Bonilla ${ }^{6}$ (D), \\ Lorenzo Gildo-Ortiz ${ }^{7}$ and Juan Reyes-Gómez ${ }^{8}$
}

check for updates

Citation: Huízar-Padilla, E.; Guillén-Bonilla, H.; Guillén-Bonilla, A.; Rodríguez-Betancourtt, V.-M.; Sánchez-Martínez, A.; Guillen-Bonilla, J.T.; Gildo-Ortiz, L.; Reyes-Gómez, J. Synthesis of $\mathrm{ZnAl}_{2} \mathrm{O}_{4}$ and Evaluation of the Response in Propane Atmospheres of Pellets and Thick Films Manufactured with Powders of the Oxide. Sensors 2021, 21, 2362. https://doi.org/ $10.3390 / \mathrm{s} 21072362$

Academic Editor: Giovanni Neri

Received: 23 February 2021

Accepted: 26 March 2021

Published: 29 March 2021

Publisher's Note: MDPI stays neutral with regard to jurisdictional claims in published maps and institutional affiliations.

Copyright: (C) 2021 by the authors Licensee MDPI, Basel, Switzerland. This article is an open access article distributed under the terms and conditions of the Creative Commons Attribution (CC BY) license (https:// creativecommons.org/licenses/by/ $4.0 /)$.
1 Facultad de Ciencias Químicas, Universidad de Colima, Colima 28400, Colima, Mexico; ehuizar@ucol.mx

2 Departamento de Ingeniería de Proyectos, CUCEI, Universidad de Guadalajara, M. García Barragán 1421, Guadalajara 44410, Jalisco, Mexico

3 Departamento de Ciencias Computacionales e Ingenierías, CUVALLES, Universidad de Guadalajara, Carretera Guadalajara-Ameca Km 45.5, Ameca 46600, Jalisco, Mexico; alex.guillen@academicos.udg.mx

4 Departamento de Química, CUCEI, Universidad de Guadalajara, M. García Barragán 1421, Guadalajara 44410, Jalisco, Mexico; veronica.rbetancourtt@academicos.udg.mx

5 CONACYT-Unidad Académica de Ciencias Químicas, Universidad Autónoma de Zacatecas, Campus Siglo XXI, Carretera Zacatecas_Guadalajara Km 6, Ejido la Escondida, Zacatecas 98160, Zacatecas, Mexico; asanchezma@conacyt.mx

6 Departamento de Electrónica, CUCEI, Universidad de Guadalajara, M. García Barragán 1421, Guadalajara 44410, Jalisco, Mexico; trinidad.guillen@academicos.udg.mx

7 Departamento de Física, CUCEI, Universidad de Guadalajara, Guadalajara 44410, Jalisco, Mexico; lorenzo.gildo@academicos.udg.mx

8 Facultad de Ciencias, Universidad de Colima, Bernal Díaz del Castillo 340, Colima 28045, Colima, Mexico; reyesgj@ucol.mx

* Correspondence: hector.guillen1775@academicos.udg.mx; Tel.: +52-33-13785900

Abstract: $\mathrm{ZnAl}_{2} \mathrm{O}_{4}$ nanoparticles were synthesized employing a colloidal method. The oxide powders were obtained at $300{ }^{\circ} \mathrm{C}$, and their crystalline phase was corroborated by X-ray diffraction. The composition and chemical structure of the $\mathrm{ZnAl}_{2} \mathrm{O}_{4}$ was carried out by $\mathrm{X}$-ray and photoelectron spectroscopy (XPS). The optical properties were studied by UV-vis spectroscopy, confirming that the $\mathrm{ZnAl}_{2} \mathrm{O}_{4}$ nanoparticles had a direct transition with bandgap energy of $3.2 \mathrm{eV}$. The oxide's microstructures were microbars of $\sim 18.2 \mathrm{~nm}$ in size (on average), as analyzed by scanning (SEM) and transmission (TEM) electron microscopies. Dynamic and stationary gas detection tests were performed in controlled propane atmospheres, obtaining variations concerning the concentration of the test gas and the operating temperature. The optimum temperatures for detecting propane concentrations were 200 and $300{ }^{\circ} \mathrm{C}$. In the static test results, the $\mathrm{ZnAl}_{2} \mathrm{O}_{4}$ showed increases in propane response since changes in the material's electrical conductance were recorded (conductance $=1$ /electrical resistance, $\Omega$ ). The increases were $\sim 2.8$ at $200{ }^{\circ} \mathrm{C}$ and $\sim 7.8$ at $300{ }^{\circ} \mathrm{C}$. The yield shown by the $\mathrm{ZnAl}_{2} \mathrm{O}_{4}$ nanoparticles for detecting propane concentrations was optimal compared to other similar oxides categorized as potential gas sensors.

Keywords: $\mathrm{ZnAl}_{2} \mathrm{O}_{4}$; nanoparticles; dynamic response; gas sensors

\section{Introduction}

For decades, the preparation processes of inorganic materials have had great relevance for obtaining optimal microstructures for potential technological applications. Traditionally, the solid-state reaction technique (or ceramic method) has been the most commonly used to synthesize different types of materials [1]. However, some research groups have reported alternative routes of synthesis, such as wet chemistry, which is simple, economical, easy to apply, and can be very efficient for obtaining high purity inorganic materials at low 
temperatures [2]. Other synthesis routes are the sol-gel, coprecipitation, ultrasonic spray, and colloidal methods [3-6]. Recently, it has been reported that the colloidal method is a very effective preparation route, with which it is possible to obtain different types of microstructures [2]. For example, reference [7] reports that by the colloidal method, it is possible to obtain different morphologies by applying the optimal synthesis conditions. In reference [8], microspheres and nanoparticles of $\mathrm{CoSb}_{2} \mathrm{O}_{6}$ are synthesized and successfully proved as gas sensors. The wet chemistry processes have allowed reducing the particle size to a nanometric scale, thus favoring the increase of both the surface area and the physical and chemical properties of the material [9]. The nanometric size of the particles increases their electrical response, in addition to the improvement of their magnetic, optical, and catalytic properties $[10,11]$. All this implies that materials with nanometric particle size can potentially be applied as gas sensors [2].

Tin oxide $\left(\mathrm{SnO}_{2}\right)$ and zinc oxide $(\mathrm{ZnO})$ nanoparticles are the most commonly used materials as gas sensors [12]. However, semiconductor oxides with more complex crystalline structures have also been suggested as alternative materials to be applied as gas detectors, like $\mathrm{LaCoO}_{3}$ [13], $\mathrm{ZnSb}_{2} \mathrm{O}_{6}$ [14], $\mathrm{CoAl}_{2} \mathrm{O}_{4}$ [15], $\mathrm{CoNb}_{2} \mathrm{O}_{6}$ [16], and more recently $\mathrm{ZnAl}_{2} \mathrm{O}_{4}$ [17]. The high response shown by these semiconductors in atmospheres of $\mathrm{CO}$, $\mathrm{CO}_{2}$, LPG, ethanol, and in humid environments is mainly due to the type of morphology, the high porosity and the nanometer size of the particles. It is important to mention that the cited works do not investigate the detection of propane gas, although reference [5] reports the detection of $\mathrm{CO}$ and propane using $\mathrm{LaCoO}_{3}$ nanoparticles.

In the case of the oxide $\mathrm{ZnAl}_{2} \mathrm{O}_{4}$ (with a bandgap of 3.5-3.9 eV [18]), its nanoparticles show interesting physical and chemical properties that make it suitable for different technological applications, mainly in the areas of solid-state lighting and displays, catalysis, ultraviolet (UV) photoelectronic devices, thermal control coatings for spacecraft, transparent conductors, optical coating devices, mechano-optical stress sensors, and microwave dielectric devices [19], among others. The oxide can be represented by the stoichiometric formula $\mathrm{XAl}_{2} \mathrm{O}_{4}$, wherein $\mathrm{X}=\mathrm{Co}, \mathrm{Ni}, \mathrm{Cu}$, or $\mathrm{Zn}$ [20]. The material generally crystallizes into a spinel-type structure with space group Fd3m [18] and has normally been prepared by the traditional method of synthesis [21], although very effective wet chemistry processes have been reported for obtaining nanoparticles of this compound [6,22].

In this work, $\mathrm{ZnAl}_{2} \mathrm{O}_{4}$ nanoparticles were synthesized using the microwave-assisted colloidal method, and their potential use as a gas sensor was studied. After thorough literature research, we found that the $\mathrm{ZnAl}_{2} \mathrm{O}_{4}$ has already been applied as a sensor for humidity and other gases. However, no evidence was found that this oxide has been previously used as a propane sensor. For this reason, we studied the dynamic and static response of $\mathrm{ZnAl}_{2} \mathrm{O}_{4}$ nanoparticles in propane atmospheres, obtaining excellent results. A high purity crystalline phase of the oxide was obtained at $300^{\circ} \mathrm{C}$. Gas detection experiments using pellets made with $\mathrm{ZnAl}_{2} \mathrm{O}_{4}$ powders showed high sensitivity when the operating temperatures and the $\mathrm{C}_{3} \mathrm{H}_{8}$ gas concentrations were varied.

\section{Experimental}

\subsection{Sample Preparation}

Spinel-type $\mathrm{ZnAl}_{2} \mathrm{O}_{4}$ was synthesized by a non-aqueous method assisted by microwave radiation. For that purpose, three $5 \mathrm{~mL}$ solutions of absolute ethyl alcohol (CTR) were prepared as a solvent for $0.01 \mathrm{~mol}$ of $\mathrm{Al}\left(\mathrm{NO}_{3}\right)_{3} \cdot 9 \mathrm{H}_{2} \mathrm{O}$ (Sigma-Aldrich, Jalmek, Guadalajara, Mexico), $0.005 \mathrm{~mol}$ of $\mathrm{Zn}\left(\mathrm{NO}_{3}\right)_{2} \cdot 6 \mathrm{H}_{2} \mathrm{O}$ (Jalmek, Guadalajara, Mexico), and $0.5 \mathrm{~mL}$ of ethylenediamine (Sigma, Guadalajara, Mexico). The solutions were stirred at $375 \mathrm{rpm}$ for $20 \mathrm{~min}$. Subsequently, the three solutions were mixed slowly to obtain a colloidal suspension, which was kept under constant stirring for $24 \mathrm{~h}$ at room temperature. After that, the solvent was evaporated by placing the suspension in a conventional domestic microwave oven (LG, model MS1147 X, Guadalajara, Mexico), applying a power of $140 \mathrm{~W}$. The solution was irradiated 40 times, lasting $60 \mathrm{~s}$ each irradiation. The energy absorbed by the solution was estimated at $336 \mathrm{~kJ}$. To avoid splashing and the consequent loss of material, 
the solution was kept at around $70{ }^{\circ} \mathrm{C}$, measuring the temperature with an Extech 403,255 infrared thermometer. The purpose of using microwave radiation in the synthesis process is to elucidate its effects on $\mathrm{ZnAl}_{2} \mathrm{O}_{4}$ 's microstructure. After evaporation, the obtained paste was dried in air at $200{ }^{\circ} \mathrm{C}$ for $8 \mathrm{~h}$, and the precursor material was afterward calcined at $300{ }^{\circ} \mathrm{C}$. The calcination was done in a Novatech programmable oven with temperature control (Tlaquepaque, Mexico), starting at room temperature and reaching $300{ }^{\circ} \mathrm{C}$ at a heating rate of $100^{\circ} \mathrm{C} / \mathrm{h}$ for $5 \mathrm{~h}$.

\subsection{Physical Characterization of $\mathrm{ZnAl}_{2} \mathrm{O}_{4}$ Powders}

Purity and crystallinity of the $\mathrm{ZnAl}_{2} \mathrm{O}_{4}$ powders were characterized by X-ray diffraction at room temperature using a Panalytical Empyrean device with $\mathrm{CuK} \alpha$ radiation $(\lambda=1.546 \AA)$. The diffraction was done using a $2 \theta$ continuous scan from $10^{\circ}$ to $80^{\circ}$ with $0.026^{\circ}$-steps at a rate of $30 \mathrm{~s}$ per step. The powders' microstructure calcined at $300{ }^{\circ} \mathrm{C}$ was analyzed by means of a field-emission scanning electron microscope (FE-SEM, Tescan MIRA 3 LMU, Mexico City, Mexico) with an acceleration voltage of $10 \mathrm{kV}$ in a high vacuum. The shape and size of the nanoparticles were studied with a transmission electron microscope (TEM, Joel JEM-ARM200F, Mexico City, Mexico) in image mode. For this, a representative amount $(0.010 \mathrm{~g})$ of the powders was placed in a vial containing methanol. Subsequently, the powders and the methanol were dispersed by an ultrasonic generator for 10 min and deposited on a 300-mesh copper grid containing a Formvar/carbon membrane.

\subsection{Chemical and Optical Characterization of the $\mathrm{ZnAl}_{2} \mathrm{O}_{4}$}

Chemical composition and surface analysis of the $\mathrm{ZnAl}_{2} \mathrm{O}_{4}$ calcined at $300{ }^{\circ} \mathrm{C}$ were studied using an X-ray photoelectron spectroscopy system (XPS SPECS, Berlin, Germany) equipped with a monochromatic $\mathrm{Al} \mathrm{K} \alpha_{1}(\mathrm{hv}=1486.7 \mathrm{eV}) \mathrm{X}$-ray source and a hemispherical energy analyzer (PHOIBOS 150). To determine the value of the forbidden bandwidth and the material's percentage of reflection, a Cary 5000 UV-vis NIR spectrophotometer (Agilent Technologies, Santa Clara, United States) was used, equipped with a polytetrafluoroethylene (PTFE) integration sphere.

\subsection{Pellets and Thick Films Preparation for Gas Sensing Tests}

For the detection tests in propane atmospheres, pellets and thick films were made from the powders calcined at $300{ }^{\circ} \mathrm{C}$. For the pellets, $0.350 \mathrm{~g}$ of $\mathrm{ZnAl}_{2} \mathrm{O}_{4}$ powders were compressed using a manual hydraulic press (Simplex Ital Equip-25 tons, Mexico City, Mexico), applying a 10-ton load for $1 \mathrm{~min}$. The dimensions of the pellets were $12 \mathrm{~mm}$ in diameter and $0.5 \mathrm{~mm}$ in thickness. For the thick films, $0.1 \mathrm{~g}$ of $\mathrm{ZnAl}_{2} \mathrm{O}_{4}$ powders was used, which was dispersed with an ultrasonic generator (Branson 2510 Ultrasonic) in a plastic container containing ethyl alcohol. The dispersed powders were then dropwise placed in a ceramic ring so that there was a contact between the radially separated electrodes at two tips ("two-tips method"). The dimensions of the thick films were $0.3 \mathrm{~mm}$ in diameter and $0.5 \mathrm{~mm}$ in thickness.

During the sensing tests in static and dynamic propane atmospheres, changes in the material's electrical resistance (in DC) were expected depending on the propane concentration, the operating temperature, and the testing time (dynamic response). For that, two ohmic contacts were placed on the pellets' surface using colloidal silver paint (Alfa Aesar, 99\%, Mexico City, Mexico). Subsequently, the pellets were placed in a small box $\left(\mathrm{V}=19 \mathrm{~cm}^{3}\right)$ placed inside the measurement chamber (see Figure 1a). The purpose of this small box was to ensure fast response times. The box had two holes: one through, which the electrodes were inserted, and which also functioned as a gas outlet; the other orifice worked as the gas inlet (see Figure $1 \mathrm{~b}$ ). The gas was then removed through the evacuation system installed in the vacuum chamber (which had a pressure of $10^{-3}$ torr). In the case of the static tests (as a function of the concentration and temperature), the total volume $(10 \mathrm{~L})$ of the vacuum chamber was used. The partial pressure of the test gases was monitored by an electronic detector (Leybold TM20, Oerlikon Leybold Vacuum, Cologne, 
Germany). The change in electrical resistance was measured with a digital multimeter (Keithley 2001, Cleveland, OH, USA) coupled to a control and acquisition system using the software LabView (National Instruments). For controlling the propane flow during the dynamic tests, a pair of massflow regulators $\left(2600\right.$ and $10 \mathrm{~cm}^{3} / \mathrm{min}$ ) were used (Brooks Instruments, GF100CXXC-SH452.6 L and GF100CXXC-SH40010C), at a total flow rate of $500 \mathrm{~cm}^{3} / \mathrm{min}$. To estimate the static response (S) as a function of concentration and operating temperature, the relative difference of the electrical conductances (1/electrical resistance, $\Omega$ ) was considered according to the formula $S=\left(G_{G}-G_{O}\right) / G_{O}[5]$, where $G_{G}$ and $\mathrm{G}_{\mathrm{O}}$ are the pellets' electrical conductance in propane and air, respectively.

For the dynamic tests with the thick films, these were placed in a quartz tube inside a tubular-type oven with programmable temperature control (Lindberg Blue M). The measurements were made at 200 and $300^{\circ} \mathrm{C}$ by the two-tips method employing high purity platinum wires with a diameter of $0.006 \mathrm{~mm}$. The control of the gas concentrations was made in the same manner as in the pellet detection tests.

(a)

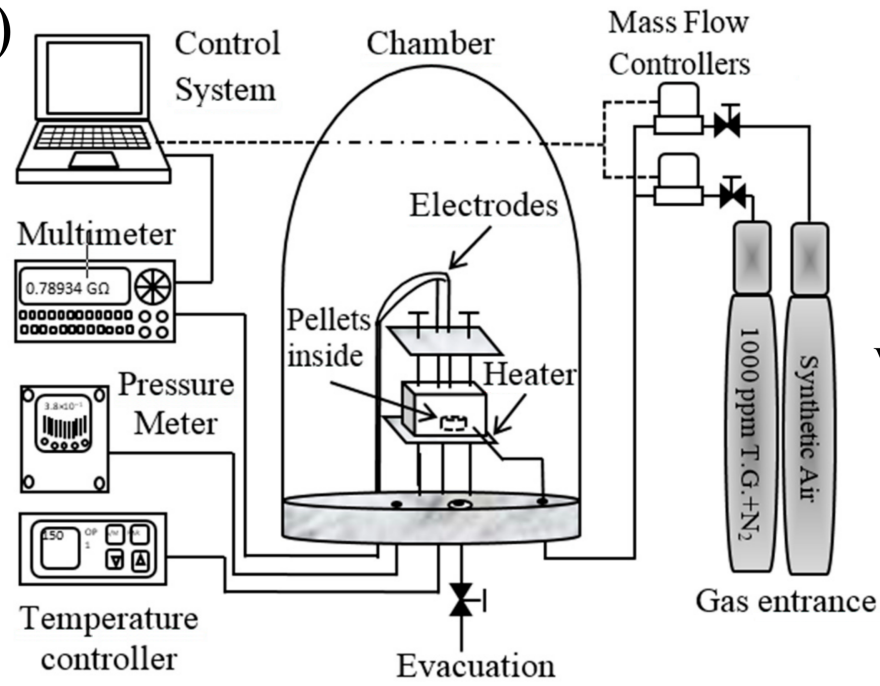

(b)

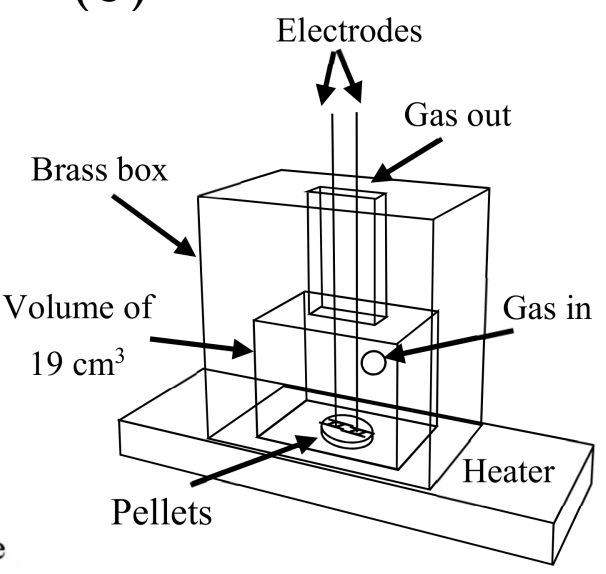

Figure 1. (a) Schematic of the system used to perform dynamic and static tests in direct current (DC) on pellets of the oxide at different concentrations and operating temperatures, and (b) Box used for the input and output of our propane gas.

\section{Results and Discussion}

\subsection{XRD Analysis}

Figure 2 shows an $\mathrm{X}$-ray diffractogram of powders calcined at $300^{\circ} \mathrm{C}$. The diffraction peaks were located at $2 \theta$ angular positions: $18.9^{\circ}, 31.2^{\circ}, 36.8^{\circ}, 38.5^{\circ}, 44.8^{\circ}, 49.07^{\circ}, 55.6^{\circ}$, $59.3^{\circ}, 32.6^{\circ}, 68.6^{\circ}, 74.1^{\circ}$, and $77.3^{\circ}$ corresponding to the crystalline planes (111), (220), (311), (222), (400), (331), (422), (511), (440), (531), (620), and (533), respectively.

The $\mathrm{ZnAl}_{2} \mathrm{O}_{4}{ }^{\prime}$ s cell parameter was calculated using the equation $[23,24]$ :

$$
a=\frac{\lambda \sqrt{\left(h^{2}+k^{2}+l^{2}\right)}}{2 \sin \theta},
$$

where $a$ is the lattice constant, $\lambda$ is the wavelength of the radiation $(1.5406 \AA),(h, k, l)$ are the Miller indices, and $\theta$ is the Bragg angle. Considering all the reflections, the estimated lattice parameter for the $\mathrm{ZnAl}_{2} \mathrm{O}_{4}$ was $8.060 \AA$ with a standard deviation of $0.007 \AA$ [24]. This result is consistent with those reported in the literature for the same compound $[18,20,21,24]$. The material's crystalline phase was identified by means of the PDF file 05-0669 corresponding to the cubic phase of the $\mathrm{ZnAl}_{2} \mathrm{O}_{4}$, with a spinel-like structure and an $\mathrm{Fd}-3 \mathrm{~m}$ (227) spatial group [22]. 


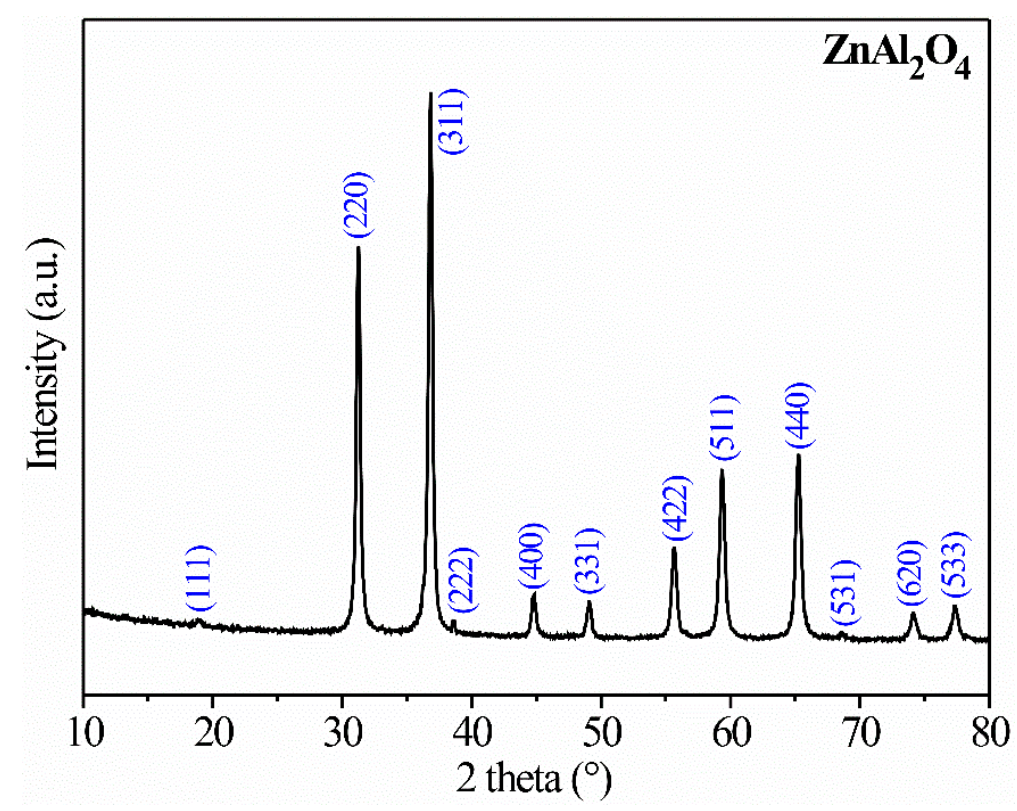

Figure 2. X-ray diffractograms of $\mathrm{ZnAl}_{2} \mathrm{O}_{4}$ powders calcined at $300{ }^{\circ} \mathrm{C}$.

The synthesis method employed in this work was successful for obtaining the spinellike crystalline structure of the $\mathrm{ZnAl}_{2} \mathrm{O}_{4}$ at a relatively low-temperature $\left(300^{\circ} \mathrm{C}\right)$ compared to other works where the same oxide was synthesized but using other preparation methods. For example, zinc aluminate has been synthesized via a coprecipitation approach followed by a heat treatment at $900{ }^{\circ} \mathrm{C}[17,18]$. $\mathrm{ZnAl}_{2} \mathrm{O}_{4}$ powders were obtained by heating a precursor in the air at $900{ }^{\circ} \mathrm{C}$ (pyrolysis) [20]. $\mathrm{MAl}_{2} \mathrm{O}_{4}(\mathrm{M}=\mathrm{Ni}, \mathrm{Cu}, \mathrm{Zn})$ spinels have been prepared by the sol-gel autocombustion method in the temperature range of $1000-1200{ }^{\circ} \mathrm{C}$ [22]. In the present study, the use of ethylenediamine contributed to the formation of the crystalline phase at relatively low temperatures. This amine is a ligand that can bind to metal ions forming coordination compounds. When the ethylenediamine reacts with a transition-metal nitrate, this produces a coordinated complex whose conformation can act as a directing agent of structure [5].

\subsection{Analysis of Chemical and Optical Properties}

To determine the chemical composition of the calcined oxide at $300{ }^{\circ} \mathrm{C}$, the XPS technique was applied. Figure 3a shows the elements on the material's surface. All spectra taken from the deep levels corresponding to $\mathrm{Al} 2 \mathrm{p}, \mathrm{Zn} 2 \mathrm{p}$, and $\mathrm{O}$ 1s were aligned with respect to the adventitious carbon $\mathrm{C} 1 \mathrm{~s}$ centered at $284.8 \mathrm{eV}$ and deconvolved with the software AAnalyzer (RDATAA, Mexico City, Mexico) [25]. The XPS spectrum associated with the $\mathrm{Zn} \mathrm{2p} \mathrm{(Figure} 3 \mathrm{~b}$ ) was deconvolved considering two doublets: The first one at 1020 and $1043 \mathrm{eV}$ associated with $\mathrm{Zn}^{2+}$ ions located at the tetrahedral sites of the $\mathrm{ZnAl}_{2} \mathrm{O}_{4}$ spinel network; the second one at 1021.3 and $1044.3 \mathrm{eV}$ associated with $\mathrm{Zn}^{2+}$ ions located at the octahedral sites in the spinel network [26,27]. Figure 3c shows the XPS spectrum associated with $\mathrm{Al} 2 \mathrm{p}$, which was deconvolved using two doublets located around 72 and $73.8 \mathrm{eV}$ at the tetrahedral and octahedral sites, respectively, and associated with $\mathrm{Al}^{3+}$ ions. The XPS spectrum associated with $\mathrm{O} 1 \mathrm{~s}$ (Figure 3d) was deconvolved using three singlets located at $529.3,531.2$, and $532.6 \mathrm{eV}$. The 529.3 and 531.2 peaks were associated with the $\mathrm{O}^{2-}$ ions on the O-Zn and O-Al bonds, so it can be assumed that these ions are located at the $\mathrm{ZnO}_{\mathrm{x}}$ and $\mathrm{AlO}_{\mathrm{x}}$ sites (tetrahedral or octahedral) in the spinel [28]. The peak located at $532.6 \mathrm{eV}$ was associated with the chemisorbed oxygen on the material's surface $[29,30]$. 

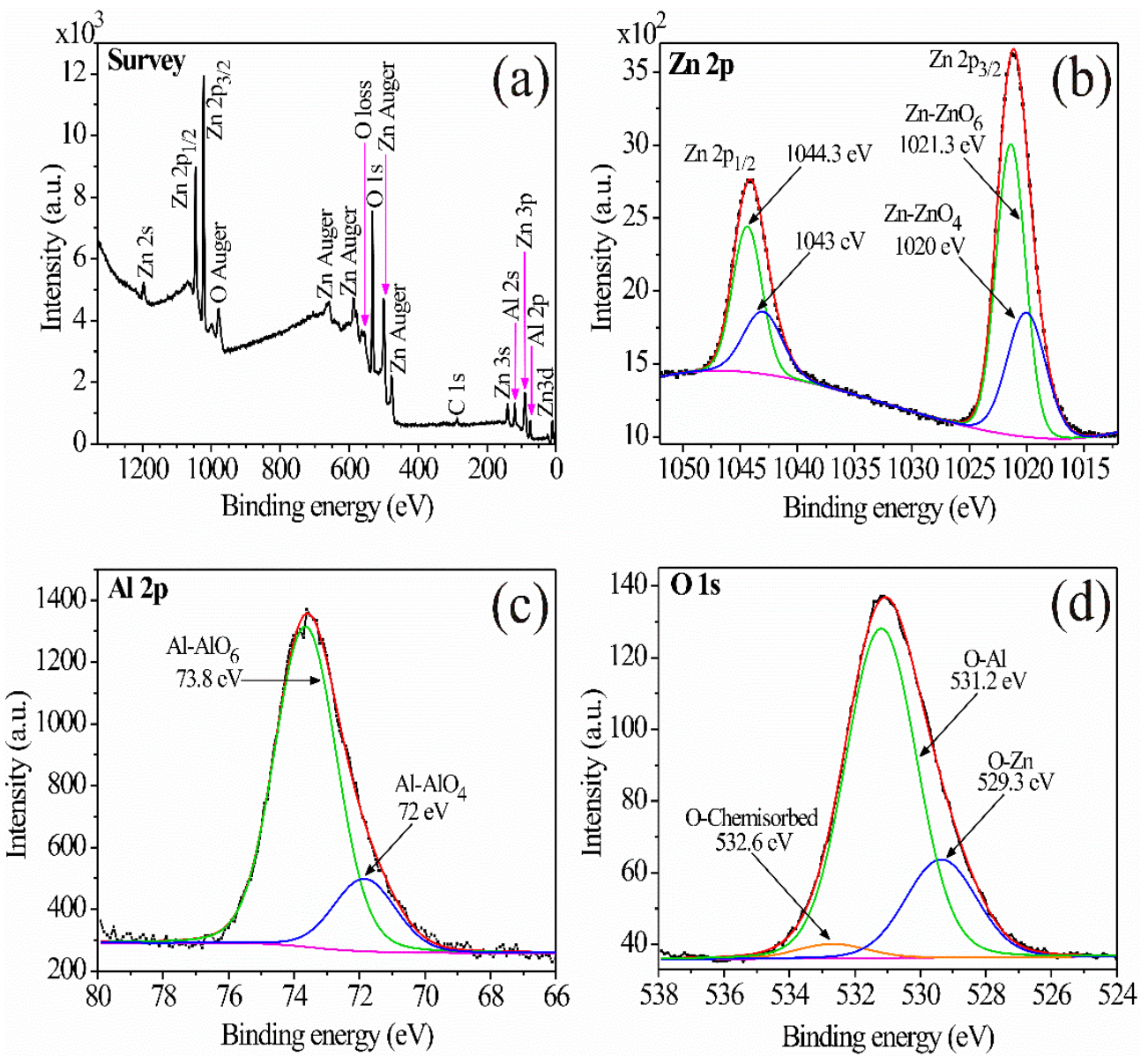

Figure 3. XPS-spectra: (a) survey, (b) $\mathrm{Zn} 2 \mathrm{p}$, (c) $\mathrm{Al} \mathrm{2p}$, (d) $\mathrm{O} 1 \mathrm{~s}$ of $\mathrm{ZnAl}_{2} \mathrm{O}_{4}$.

The percentage of reflection and the forbidden bandwidth were determined from $\mathrm{UV}$-vis spectra. Figure 4 shows the UV-vis reflectance spectrum of $\mathrm{ZnAl}_{2} \mathrm{O}_{4}$, where an increase in the percentage of reflection from 400 to $700 \mathrm{~nm}$ towards infrared and a strong absorption from $400 \mathrm{~nm}$ towards ultraviolet can be observed. To determine the value of the forbidden bandwidth, the Kubelka-Munk (K-M) theory was considered in which the absorption coefficient is proportional to the reflectance [31]. Hence, from Tauc's formula, $\alpha(h v) \approx B\left(h v-E_{g}\right)^{n}$, and if $\alpha \approx F(R)=\frac{(1-R)^{2}}{2 R}$, where $R$ is the reflectance and $n=1 / 2$ for a direct transition, the forbidden bandwidth's value $E_{g}$ for the spinel $\mathrm{ZnAl}_{2} \mathrm{O}_{4}$ was obtained from the graph of $(F(R) h v)^{2}$ versus $h v$. As can be seen in Figure 4 (see inset), the value was $3.2 \mathrm{eV}$, which is less than the theoretically predicted value but similar to that experimentally reported [32,33]. 


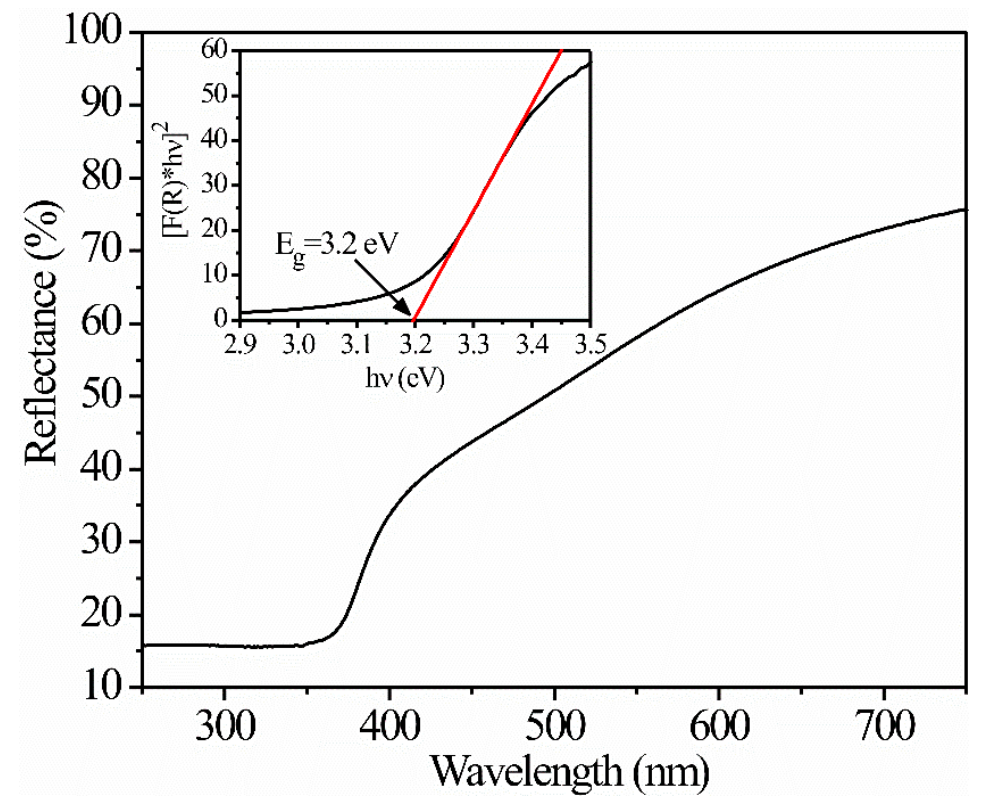

Figure 4. Reflection spectrum and relation $\mathrm{F}(\mathrm{R})^{*} \mathrm{hv}$ vs. wavelength (inset) of the $\mathrm{ZnAl}_{2} \mathrm{O}_{4}$.

\subsection{SEM Analysis}

Figure 5 shows SEM images of the $\mathrm{ZnAl}_{2} \mathrm{O}_{4}$ obtained by calcination at $300{ }^{\circ} \mathrm{C}$. For the analysis of the material's microstructure, four different magnifications were employed: (a) $6.42 \mathrm{kX},(\mathrm{b}) 4.21 \mathrm{kX}$, (c) $20.5 \mathrm{kX}$, and (d) $26.4 \mathrm{kX}$.
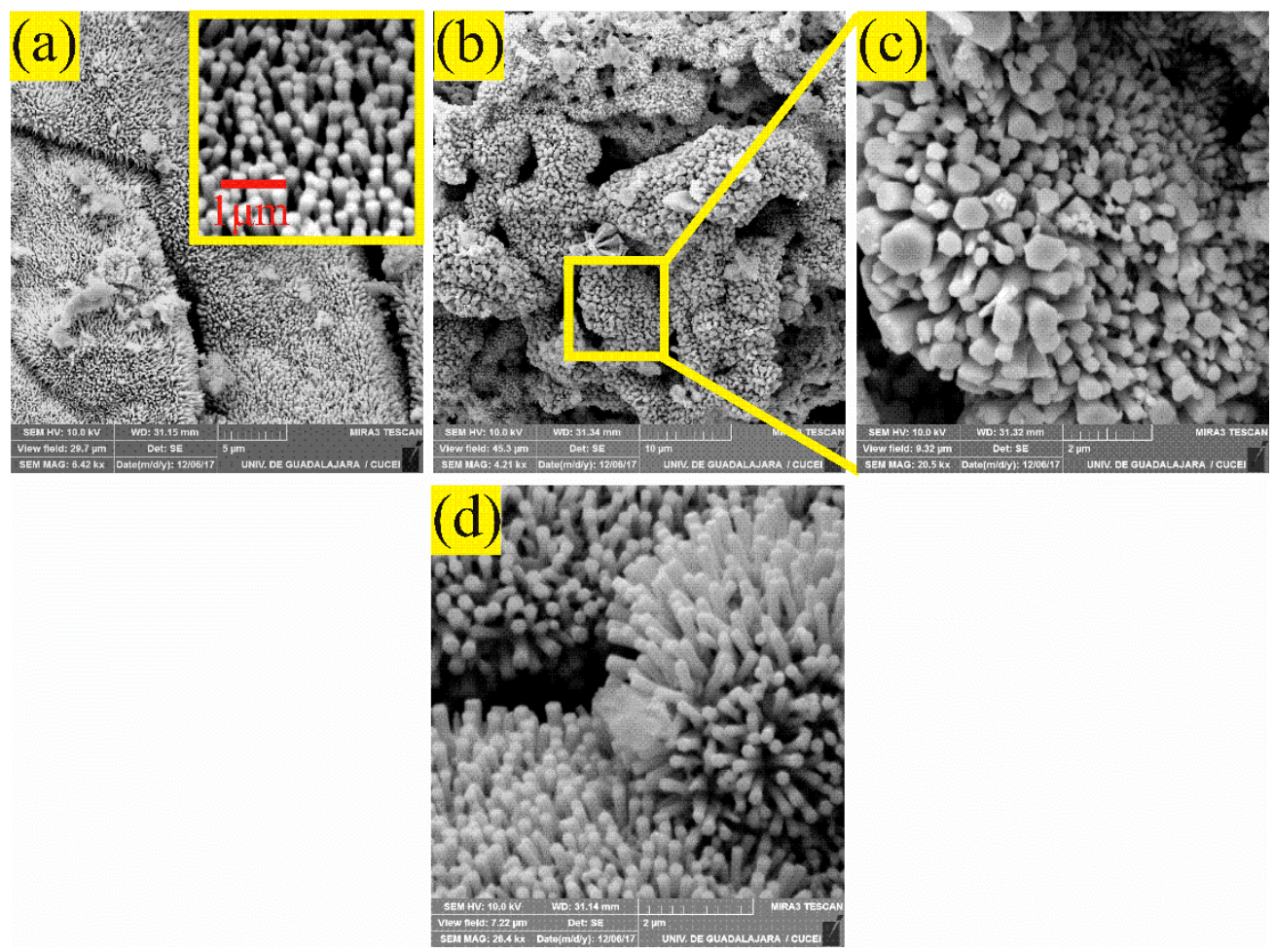

Figure 5. SEM images showing the formation of microrods at $300^{\circ} \mathrm{C}$, at magnifications: (a) $6.42 \mathrm{kX}$, (b) $4.21 \mathrm{kX},($ c) $20.5 \mathrm{kX}$, and (d) $26.4 \mathrm{kX}$.

These photomicrographs show the multidirectional growth of a large number of microrods, which are distributed throughout the material's surface (similar to a tapestry, see Figure $5 a, b)$. These microrods are positioned next to each other, almost in an orderly 
manner, causing a coated surface of the microstructure, as shown in the inset of Figure 5a. It can also be observed that the microrods grow from areas located on microplates that act as a substrate. Such microrods agglomerate in a way that they tend to form a sphere-like geometry (see Figure 5b,c). Analyzing several SEM images, the length of the microrods was estimated in the range of 0.048 to $1.05 \mu \mathrm{m}$, with an average size of $\sim 0.678 \mu \mathrm{m}$ and a standard deviation of $\sim 0.20 \mu \mathrm{m}$ (see Figure 6). Observing another area of material's surface, it is corroborated that the compound's microstructure is formed by microrods that grow due to the effect of the temperature and the ethylenediamine concentration used during the synthesis process. The diameter of the microrods was estimated at $\sim 0.398 \mu \mathrm{m}$ on average. In general, it is observed that the surface of the $\mathrm{ZnAl}_{2} \mathrm{O}_{4}$ shows the same morphology, which can be seen in Figure $5 \mathrm{~d}$. In particular, the use of ethylenediamine as a way to produce 1D structures, such as rods, tubes, and wires, has been previously reported in the literature $[34,35]$. In our case, ethylenediamine acts as a template that is first incorporated into the inorganic network to later escape from it forming morphologies, such as the ones shown in Figure 5. Therefore, the presence of ethylenediamine determines the geometric features of the formed nuclei, which grow during the heat treatments [5]. We also have reported in previous works that by using ethylenediamine during the synthesis process, it is possible to obtain different types of morphologies [5,36-38], like microrods, nanorods, microspheres, microoctahedra, and nanoparticles, which have been successfully proved as potential gas sensors for the detection of $\mathrm{CO}, \mathrm{CO}_{2}$, and $\mathrm{C}_{3} \mathrm{H}_{8}$ atmospheres [39]. Additionally, other authors, such as Michel et al. [40], used ethylenediamine for the synthesis of the semiconductor oxide $\mathrm{CoSb}_{2} \mathrm{O}_{6}$ in order to obtain nanoparticles to be applied in the detection of $\mathrm{CO}_{2}$ and $\mathrm{O}_{2}$. In general, the microstructure shown in Figure 5 follows the crystallization principles described by LaMer and Dinegar [41].

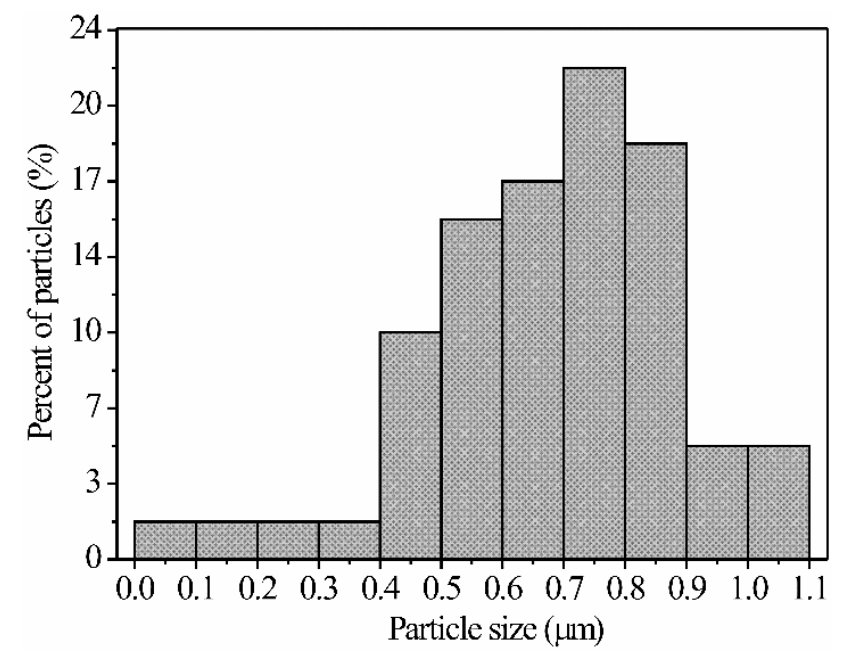

Figure 6. Size distribution of the $\mathrm{ZnAl}_{2} \mathrm{O}_{4}$ microrods obtained at $300{ }^{\circ} \mathrm{C}$.

\subsection{TEM Analysis}

For a more detailed analysis of the individual particles that made up the $\mathrm{ZnAl}_{2} \mathrm{O}_{4}$ oxide, transmission electron microscopy (TEM) was employed. Figure 7 show typical bright-field TEM images of the oxide calcined at $300{ }^{\circ} \mathrm{C}$. 

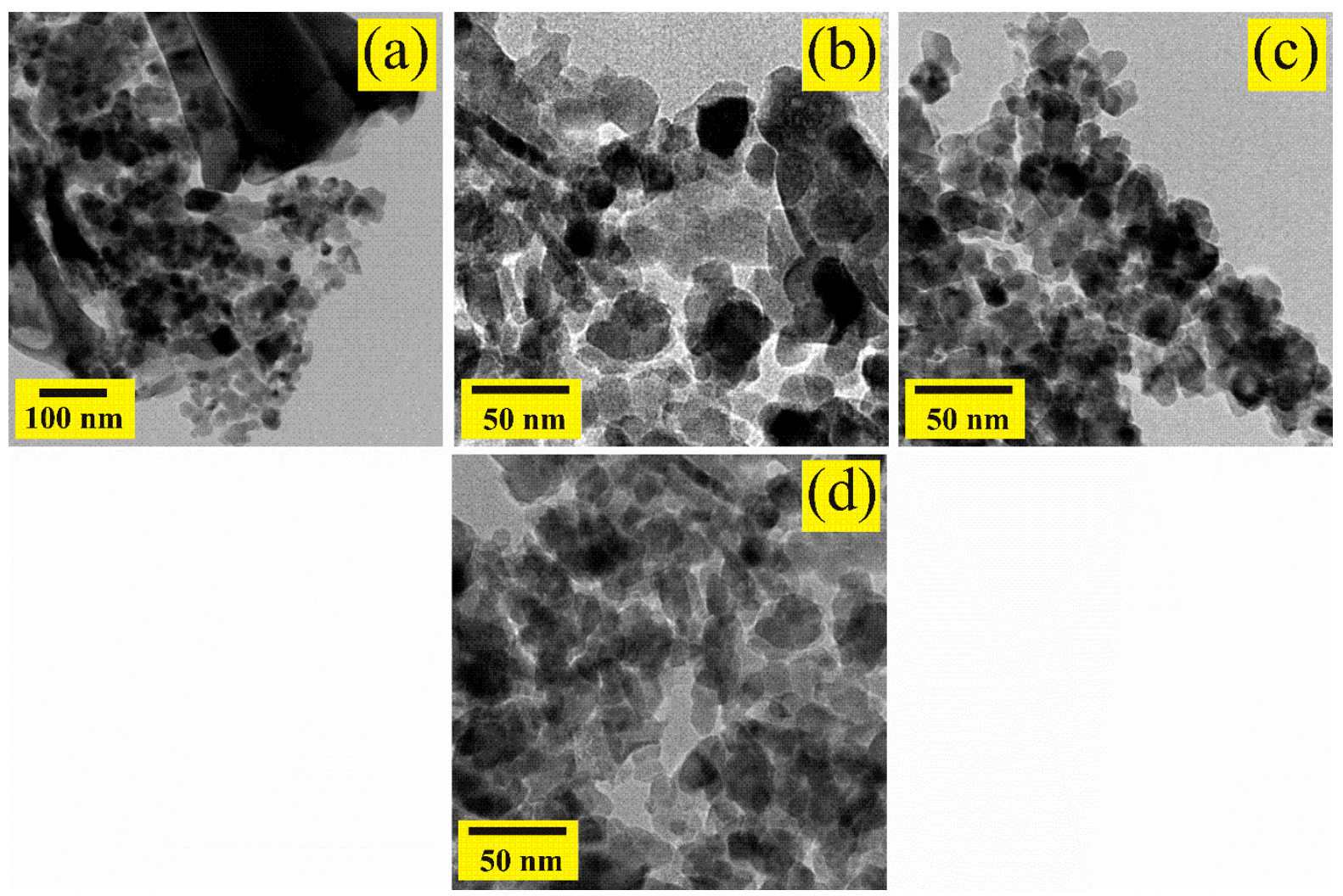

Figure 7. TEM images showing the individual characteristics of the $\mathrm{ZnAl}_{2} \mathrm{O}_{4}$ nanoparticles calcined at $300{ }^{\circ} \mathrm{C}$ : (a) growth of rods and nanoparticles, (b) agglomeration of nanoparticles to form the rods, (c) agglomeration of individual nanoparticles, (d) nucleation of different nanoparticle morphologies.

In the TEM images, dark areas are observed that are attributed to the poor transmission of electrons caused by the agglomeration of nanoparticles on the material's surface. It is mentioned in the literature that, when using ethylenediamine during the synthesis process, particle agglomeration occurs, where the thermal treatment (in our case at $300{ }^{\circ} \mathrm{C}$ ) plays a key role in obtaining agglomerated areas of nanoparticles, as shown in Figure 7a-d [37,39]. In a more detailed study of the TEM images, we corroborated our SEM analysis where the rod growth and nucleation are observed, as well as other nanoparticles with no apparent shape (Figure 7a). Furthermore, it can be seen that the nanoparticles agglomerated one with the other until the nanorod morphology shown in Figure $7 \mathrm{~b}$ was obtained. Regarding Figure $7 \mathrm{c}, \mathrm{d}$, it is observed that the surface of the $\mathrm{ZnAl}_{2} \mathrm{O}_{4}$ is made up of irregularly shaped nanometric-sized particles, which are joined by coalescence. The visible dispersion of the nanoparticles is attributed to the preparation technique for the TEM analysis, which required that the $\mathrm{ZnAl}_{2} \mathrm{O}_{4}$ was dispersed by ultrasound. The particle size, in a range from 5 to $35 \mathrm{~nm}$ (with an average of $\sim 18.2 \mathrm{~nm}$ and a standard deviation of $\sim 6.5 \mathrm{~nm}$ ), was estimated by examining several TEM images (Figure 8 ).

Figure 9 shows high-resolution TEM images (HRTEM) of the $\mathrm{ZnAl}_{2} \mathrm{O}_{4}$ nanoparticles obtained at $300{ }^{\circ} \mathrm{C}$, a typical electron diffraction pattern of the oxide, and a histogram that corroborates the interplanar spacing of the $\mathrm{ZnAl}_{2} \mathrm{O}_{4}$. In Figure $9 \mathrm{a}, \mathrm{b}$, it can be seen that the material's surface consisted of very fine and irregular nanoparticles $(\sim 20 \mathrm{~nm}$ in size). The borders between the individual nanoparticles were drawn with yellow-dotted lines. We could corroborate in these individual nanoparticles the presence of the oxide's crystalline planes. Selecting some areas of the particle surfaces, we could estimate the distance between the planes at $\sim 0.47 \mathrm{~nm}$, which corresponded to the crystalline plane (111) of the spinel's crystal structure, as shown in Figure 9a-d. Figure 9e shows a typical electrondiffraction pattern of the $\mathrm{ZnAl}_{2} \mathrm{O}_{4}$ nanoparticles, where the characteristic reflection rings of a nanometric polycrystalline material are observed. Accordingly, the first six reflections 
corresponding to the crystalline planes (111), (220), (311), (400), (331), and (422) were indexed, confirming the sample's local crystallinity, consistently with the XRD study (see Figure 2).

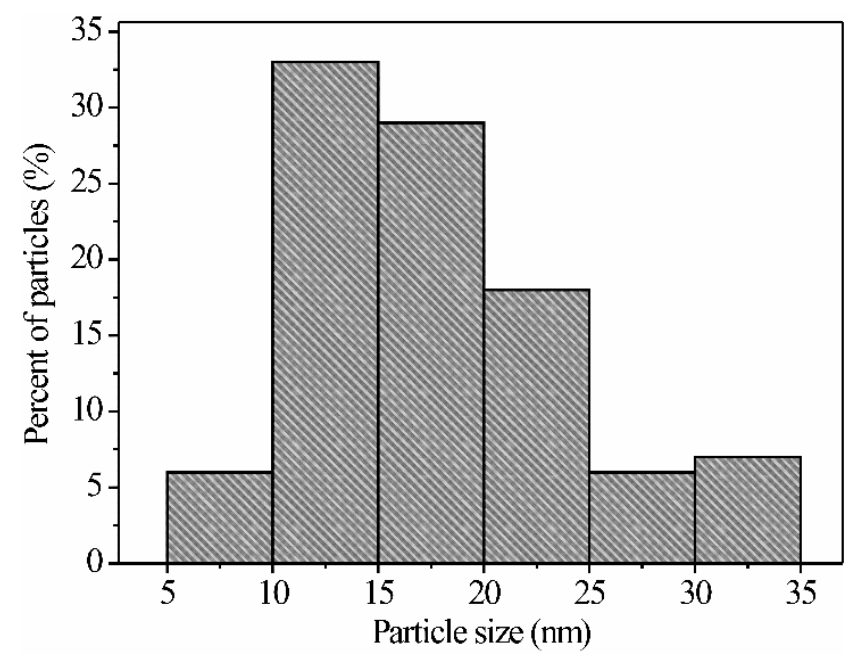

Figure 8. Nanoparticle size distribution for the $\mathrm{ZnAl}_{2} \mathrm{O}_{4}$ calcined at $300{ }^{\circ} \mathrm{C}$.

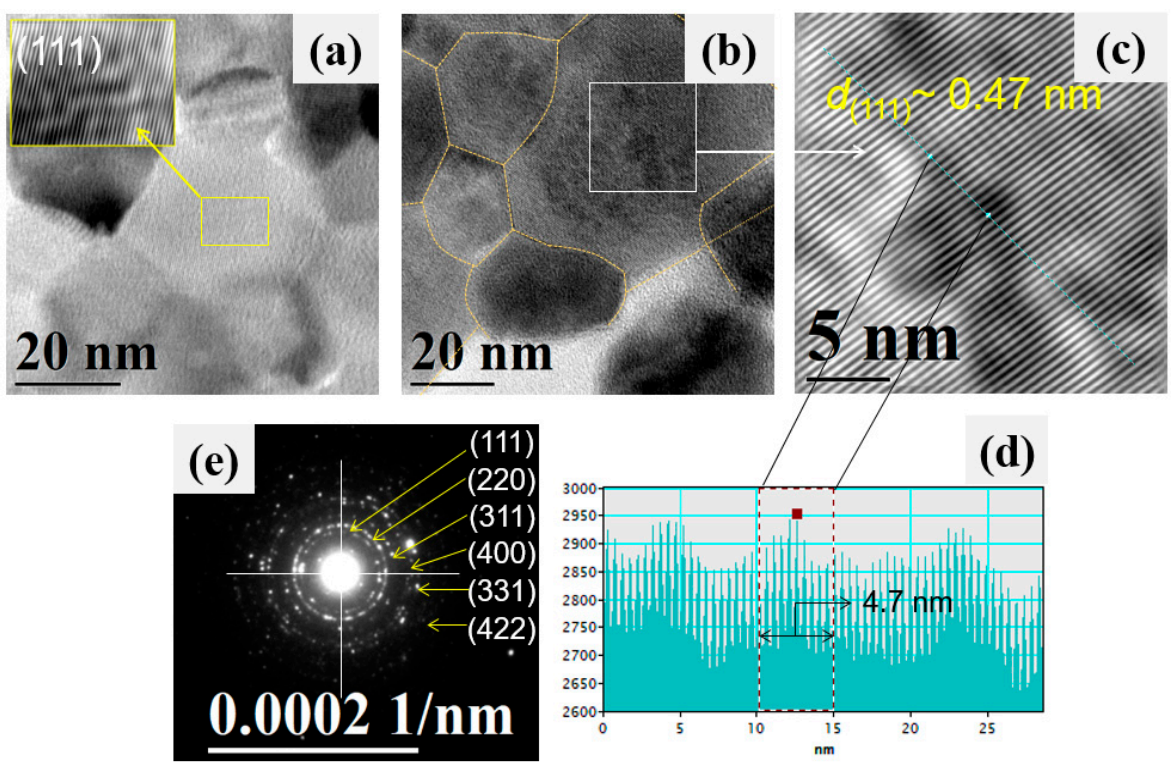

Figure 9. (a,b) TEM images showing the grain boundaries of the $\mathrm{ZnAl}_{2} \mathrm{O}_{4}$ nanoparticles, (c) HRTEM image where the oxide's crystalline planes can be clearly identified, (d) histogram to estimate the crystals' interplanar spacing, (e) electron diffraction pattern (SAED) from a selected area on the surface of a nanoparticle.

\subsection{Gas Sensing Tests}

The results of the static detection tests on the $\mathrm{ZnAl}_{2} \mathrm{O}_{4}$ pellets at different operating temperatures and propane concentrations are shown in Figure 10. The propane concentrations were $1,5,50,100,200,300,400$, and 500 ppm, while the temperatures were 100, 200, and $300{ }^{\circ} \mathrm{C}$. As can be seen in Figure 10 , the $\mathrm{ZnAl}_{2} \mathrm{O}_{4}$ shows an increase in its response as the propane concentration and the working temperature increase during the test. However, at $100{ }^{\circ} \mathrm{C}$, the pellets did not show changes in electrical resistance with increasing concentration and operating temperature (see Figure 10a,b). This behavior is attributed to the fact that the relatively low-temperature is not enough for the reaction of the pellets' surface and the test gas. This caused that at $100{ }^{\circ} \mathrm{C}$, oxygen desorption did not occur [38,39] and, therefore, a low response of the material. Some authors also observed the poor response 
that shows some semiconductors at low temperatures (in our case at $100{ }^{\circ} \mathrm{C}$ ), such as ours. They attributed such phenomenon to the fact that the oxygen species present (usually $\mathrm{O}_{2}^{-}$[2]) do not react with the test gas nor with the pellets' surface (that is, adsorption and desorption processes do not occur) $[5,10,12,17]$, provoking the absence of changes in the material's electrical resistance [5,36] (see Figure 10). On the contrary, when increasing the operating temperature to 200 and $300{ }^{\circ} \mathrm{C}$, a very significant increase in the response of the pellets was recorded (see Figure 10a,b). The increases in response are largely due to the fact that, with increasing thermal energy, $\mathrm{O}^{-}$oxygen species are easily adsorbed on the surface of the pellets [2,42]. These species are more reactive and capable of causing a greater speed in the mobility of charge carriers, having as a consequence an improvement in sensitivity, which in turn promotes an increase in the response of the $\mathrm{ZnAl}_{2} \mathrm{O}_{4}$. Therefore, by increasing the temperature to $300{ }^{\circ} \mathrm{C}$, the response increased 2.7 times more than that measured at $200{ }^{\circ} \mathrm{C}\left(2.8\right.$ at $200{ }^{\circ} \mathrm{C}$ and 7.8 at $300{ }^{\circ} \mathrm{C}$, both at $500 \mathrm{ppm}$ of propane). The response increase is associated with the increase in the concentration of the propane gas that reacts with chemisorbed oxygen (ionic oxygen) on the material's surface due to the rise of temperature. That caused variations in the semiconductor's electrical resistance (or conductivity) and the increase of the sensor's response $[5,14,15,36]$. The trend shown in Figure 10 is consistent with the results of similar oxides reported in the literature $[2,5,36,43]$.
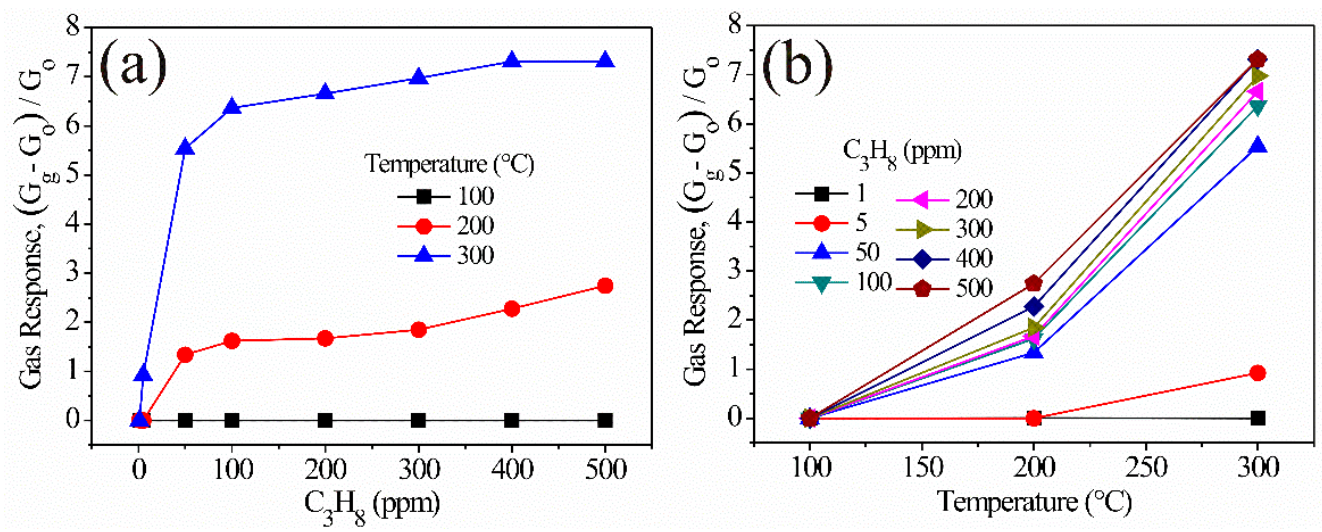

Figure 10. Response of $\mathrm{ZnAl}_{2} \mathrm{O}_{4}$ pellets as a function of (a) propane concentration, (b) operating temperature.

As seen in Figure 10a, at a propane concentration of $50 \mathrm{ppm}$, and at 200 and $300{ }^{\circ} \mathrm{C}$, the response increased significantly. However, when the concentration was increased to 200, 300,400 , and 500 ppm, no significant changes were observed. Even at $300{ }^{\circ} \mathrm{C}$, there was no change in the response from 400 to $500 \mathrm{ppm}$. This could be explained by the saturation of the sensor's surface. Desorption and adsorption of gas molecules were in equilibrium at these concentrations, which meant that additional molecules could not be adsorbed directly at the sensor's surface, causing a delayed contribution to resistance changes.

Dynamic tests on pellets and thick films made from $\mathrm{ZnAl}_{2} \mathrm{O}_{4}$ powders were carried out alternatively in air-propane atmospheres by the two-tips method using a direct current signal (DC). The variation of the electrical resistance was monitored while injecting synthetic air $\left(20 \% \mathrm{O}_{2}, 80 \% \mathrm{~N}_{2}\right)$ as a stabilizing gas for the pellets (500 $\mathrm{mL} / \mathrm{min}$ of synth. air) and the films $(1500 \mathrm{~mL} / \mathrm{min}$ of synth. air). Propane's concentration was $1000 \mathrm{ppm}$ in balance with $\mathrm{N}_{2}$ (air-propane) at 200 and $300{ }^{\circ} \mathrm{C}$ in both cases. Material's dynamic response was measured as follows: first, the pellets and the thick films were stabilized in synthetic air for $5 \mathrm{~min}$ at each temperature; subsequently, propane was injected for $5 \mathrm{~min}$, provoking changes in the electrical resistance of the pellets and the thick films; then, the propane was withdrawn leaving the pellets and the thick films stabilizing in synthetic air for 5 min up to reaching the initial values of the electrical resistance. This process was repeated cyclically for each temperature $\left(200\right.$ and $\left.300{ }^{\circ} \mathrm{C}\right)$. Figures 11 and 12 show the change in electrical resistance as a function of time at the given temperatures and propane concentration. As can be observed, the cycle repetitions are indicative of good reproducibility. In addition, as 
expected, in both cases, the oxide powders showed a decrease in electrical resistance (or an increase in conductivity) when the propane was introduced into the measurement chamber. The change was more noticeable at $300{ }^{\circ} \mathrm{C}$. According to Figure $11 \mathrm{a}, \mathrm{b}$, the variations in electrical resistance were estimated at $0.126 \mathrm{M} \Omega$ (on average) at $200^{\circ} \mathrm{C}$, while at $300{ }^{\circ} \mathrm{C}$ it was calculated at $6.677 \mathrm{M} \Omega$. The response and recovery times were calculated according to reference [44], which considered the changes in electrical resistance as a function of time. As in reference [45], we considered $90 \%$ of the total response and $10 \%$ of the saturation values in air. Therefore, when applying these criteria to the results shown in Figure 11, we estimated the response and recovery times at $200{ }^{\circ} \mathrm{C}$ were 206 and $160 \mathrm{~s}$. At $300{ }^{\circ} \mathrm{C}$, response and recovery times were $176 \mathrm{~s}$ and $205 \mathrm{~s}$.
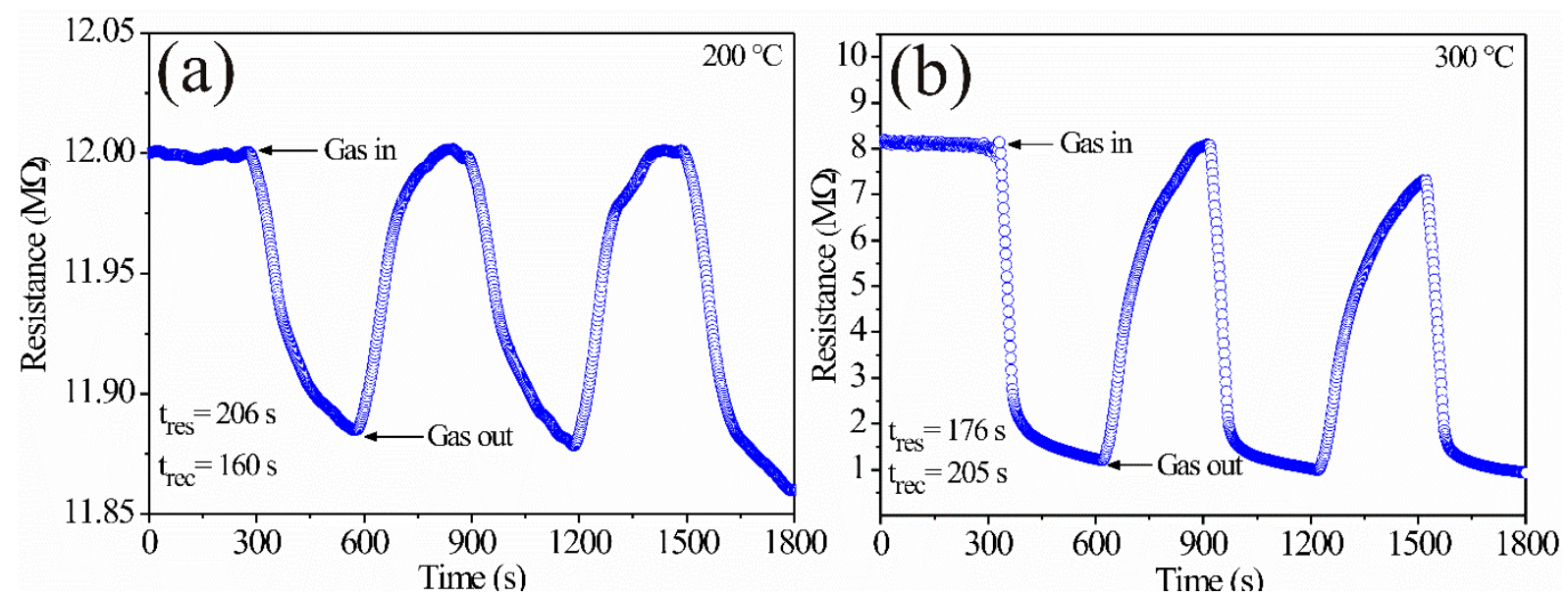

Figure 11. Dynamic response of $\mathrm{ZnAl}_{2} \mathrm{O}_{4}$ pellets in an air-propane mixture at temperatures: (a) $200{ }^{\circ} \mathrm{C},(\mathbf{b}) 300{ }^{\circ} \mathrm{C}$.
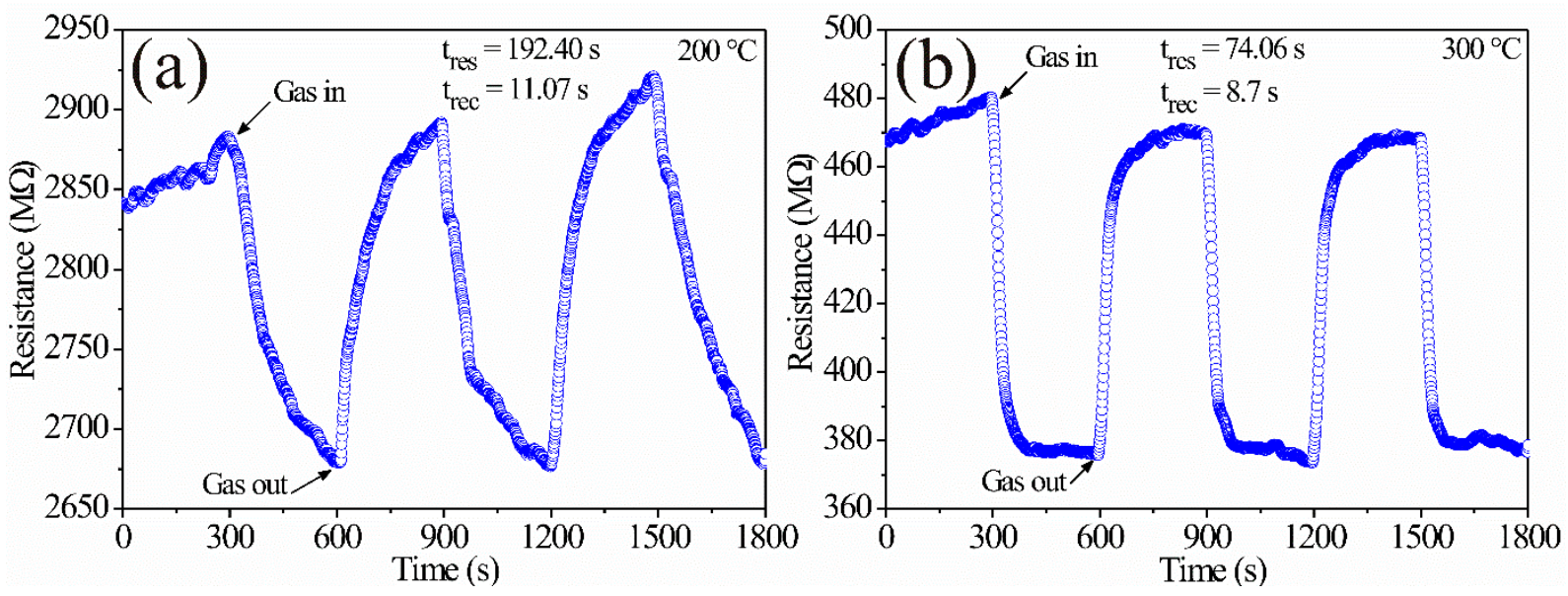

Figure 12. Dynamic response of $\mathrm{ZnAl}_{2} \mathrm{O}_{4}$ thick films in air-propane atmospheres at temperatures: (a) $200{ }^{\circ} \mathrm{C},(\mathbf{b}) 300{ }^{\circ} \mathrm{C}$.

Similar trends were obtained on the thick films. The results are depicted in Figure 12a,b, where changes in electrical resistance are observed as a function of time at different operating temperatures. It can be verified that the effect of temperature and propane concentration played an important role during the tests. As in the pellets' case, the changes in the electrical resistance fluctuated due to the reaction that occurred between propane and oxygen on the thick film's surface at the given operating temperature, causing a decrease in electric resistance as a function of time. The average variation of the electrical resistance at $200{ }^{\circ} \mathrm{C}$ was $174.03 \mathrm{k} \Omega$, with a response time of $192.40 \mathrm{~s}$ and a recovery time of $11.07 \mathrm{~s}$, while at $300{ }^{\circ} \mathrm{C}$ it was $96.05 \mathrm{k} \Omega$, with a response time of $74.06 \mathrm{~s}$ and a recovery time of $8.7 \mathrm{~s}$. Again, as in the case of the dynamic response on the pellets, we considered references $[44,45]$ to calculate the response and recovery times. 
The response depicted in Figures 11 and 12 is commonly observed in type-n semiconductor oxides [33] when they are exposed to atmospheres similar to ours [14,43]. Again, we consider that the increase in operating temperature (in our case from 200 to $300{ }^{\circ} \mathrm{C}$ ) was a determining factor in the pellet's response due to the presence of oxygen during the tests. References [2,46] report that several oxygen species appear as a consequence of the temperature during gas detection experiments: when testing at temperatures below $150{ }^{\circ} \mathrm{C}$, the predominant oxygen species is $\mathrm{O}_{2}^{-}$, while at temperatures greater than $150{ }^{\circ} \mathrm{C}$, the predominant oxygen species are $\mathrm{O}^{-}$and $\mathrm{O}^{2-}$, which are more reactive than $\mathrm{O}_{2}^{-}[5,36,46]$; oxygen reactions produced at temperatures above $150{ }^{\circ} \mathrm{C}$ (in our case 200 and $300{ }^{\circ} \mathrm{C}$ ) cause an increase in the reaction kinetics of the gas molecules on the pellet surfaces and thereby a sensitivity increase. It has been reported that other factors that affect the test gas chemisorption are both the presence of oxygen and the material's microstructure (size and morphology) [47] since if the particle size is less than 2 times the thickness of the outer layer $\left(\mathrm{L}_{\mathrm{S}}\right)$, the adsorbed oxygen species are those that lead to a greater material's response $[43,48]$, as occurred in our case.

In the case of the pellets, the sensor's resistance varied from $\sim 8 \mathrm{M} \Omega$ without gas to $\sim 1 \mathrm{M} \Omega$ in propane at $300{ }^{\circ} \mathrm{C}$ (Figure $11 \mathrm{~b}$ ); the ratio $\mathrm{R}_{0} / \mathrm{R}_{\mathrm{G}}$ was 8 . Instead, for the thick films, at the same temperature and propane concentration, the change in the resistance varied from $\sim 480 \mathrm{M} \Omega$ to $\sim 380 \mathrm{M} \Omega$ (Figure $12 \mathrm{~b}$ ); the ratio $\mathrm{R}_{0} / \mathrm{R}_{\mathrm{G}}$ was 1.26 . The increased pellet response could be attributed to the preparation of the sensor: pressure was applied to the powder, which should decrease the average distance between the particles. The current between the grains must be strongly controlled by the Schottky barriers between the grains of the material. On the other hand, the thick films were drip prepared. As a consequence, their particles had, on average, a greater distance (i.e., there was less contact) between them. Therefore, higher electrical resistance was generated with the associated tunneling effect. Another effect of the grain compaction was observed in the response times: there was greater gas mobility through the film (associated with more pores) compared to the pellets.

In general, the response of a semiconductor material (such as the one studied in this work) is based on the mechanism that involves changes in the conductance (or electrical resistance) produced by the electron transfer that occurs during chemical adsorption $[8,14,43]$. Depending on the semiconductor type ( $p$ or $n$ ), the surface charge carriers may increase or decrease, as appropriate [14]. The mobility and variations of the charge carriers depend on the temperature [49], the morphology, and the particle size of the semiconductor (which in our case was $\sim 18.2 \mathrm{~nm}$ ) $[47,49,50]$. This means that the interaction between the oxygen and the semiconductor's surface will be more active due to the effect of temperature. That will provoke more significant changes in the semiconductor's electrical resistance, therefore, meaning a greater response, as happened in this work.

The sensitivity of the $\mathrm{ZnAl}_{2} \mathrm{O}_{4}$ prepared in this work was compared with previous studies on propane gas sensing. For example, thin-films of $\mathrm{SnO}_{2}$ showed a sensitivity of 0.7 at a propane concentration of $300 \mathrm{ppm}$ at a temperature of $300{ }^{\circ} \mathrm{C}$ [51]. At the same experimental conditions, thin-films of $\mathrm{ZnO}$ exhibited a response of 0.4 [52]. The trirutile-type $\mathrm{ZnSb}_{2} \mathrm{O}_{6}$ [53] and $\mathrm{CoSb}_{2} \mathrm{O}_{6}$ [54] showed responses of 1.3 and 4.8, respectively, to 300 ppm of propane at temperatures between 250 and $300{ }^{\circ} \mathrm{C}$. The cited studies do not report information on response and recovery times. The results obtained in the present study highlight the synthesized spinel as a promising material in gas sensing applications.

\section{Conclusions}

In this work, $\mathrm{ZnAl}_{2} \mathrm{O}_{4}$ nanoparticles were synthesized by the microwave-assisted colloidal method, which is a simple and economical process that does not require sophisticated equipment for obtaining both nanometric particle sizes and the crystalline phase at low temperatures. The powders were studied chemically by XPS, which provided information on the oxidation states of the $\mathrm{Zn}$ and the Al. The bandgap of the oxide was determined by UV-vis, obtaining a value of $3.2 \mathrm{eV}$. The oxide nanoparticles showed an increase in sensitivity as the propane concentration and the operating temperature were also raised. 
The maximum sensitivity value in the static test was $\sim 7.8$ for a propane concentration of $500 \mathrm{ppm}$ at $300{ }^{\circ} \mathrm{C}$. The dynamic tests on pellets and thick films of $\mathrm{ZnAl}_{2} \mathrm{O}_{4}$ revealed that with the increase in operating temperature and test gas concentration, the response of the nanoparticles improved substantially, which was reflected in the changes in their electrical resistance. The best response was at a temperature of $300{ }^{\circ} \mathrm{C}$ with short response and recovery times. According to our results, $\mathrm{ZnAl}_{2} \mathrm{O}_{4}$ nanoparticles can be a viable option to be used as a propane sensor.

Author Contributions: Investigation, J.R.-G., H.G.-B. and E.H.-P.; Formal analysis, V.-M.R.-B., J.T.G.-B. and A.S.-M.; Synthesis, A.G.-B., L.G.-O. and A.S.-M.; Preparation of materials for gas sensors, E.H.-P., A.G.-B. and L.G.-O.; Initial draft writing, E.H.-P., H.G.-B. and J.R.-G.; Review and editing, E.H.-P., V.-M.R.-B. and H.G.-B. All authors have read and agreed to the published version of the manuscript.

Funding: This research was funded by the National Council of Science and Technology of Mexico (CONACYT), grant number 782789.

Institutional Review Board Statement: Not applicable.

Informed Consent Statement: Not applicable.

Data Availability Statement: The data that support the findings of this study are available from the corresponding authors upon request.

Acknowledgments: The authors thank Mexico's National Council of Science and Technology (CONA$C y T)$, the University of Colima, and the University of Guadalajara for the support granted. Emilio Huízar Padilla thanks CONACyT for a PhD scholarship \# 614090. Likewise, we thank M. de la Luz Olvera Amador, Juan Pablo Moran Lázaro, Dario Pozas Zepeda, and Miguel-Ángel Luna Arias for their technical assistance. This investigation was carried out following the lines of research "Nanostructured Semiconductor Oxides" of the academic group UDG-CA-895 "Nanostructured Semiconductors" of CUCEI, University of Guadalajara and "Physicochemistry of materials, organic and metallic systems" UCOL-CA-112 "Theoretical and Applied Physicochemistry" the University of Colima.

Conflicts of Interest: The authors declare that there are no conflicts of interest regarding the publication of this article.

\section{References}

1. Rounaghi, S.A.; Vanpoucke, D.E.P.; Esmaeili, E.; Scudino, S.; Eckert, J. Synthesis, characterization and thermodynamic stability of nanostructured $\varepsilon$-iron carbonitride powder prepared by a solid-state mechanochemical route. J. Alloys Compd. 2019, 778, 327-336. [CrossRef]

2. Wetchakun, K.; Samerjai, T.; Tamaekong, N.; Liewhiran, C.; Siriwong, C.; Kruefu, V.; Wisitsoraat, A.; Tuantranont, A.; Phanichphant, A. Semiconducting metal oxides as sensors for environmentally hazardous gases. Sens. Actuators B Chem. 2011, 160, 580-591. [CrossRef]

3. Xavier-Stango, S.A.; Vijayalakshmi, U. Synthesis and characterization of hydroxyapatite/carboxylic acid functionalized MWCNTS composites and its triple layer coatings for biomedical applications. Ceram. Int. 2019, 45, 69-81. [CrossRef]

4. Korotcenkov, G.; Cho, B.K. Metal oxide composites in conductometric gas sensors: Achievements and challenges. Sens. Actuators B Chem. 2017, 244, 182-210. [CrossRef]

5. Gildo-Ortiz, L.; Guillén-Bonilla, H.; Rodríguez-Betancourtt, V.M.; Blanco-Alonso, O.; Guillén-Bonilla, A.; Santoyo-Salazar, J.; X Romero-Ibarra, V.M.; Reyes-Gómez, J. Key processing of porous and fibrous $\mathrm{LaCoO}_{3}$ nanostructures for successful CO and propane sensing. Ceram. Int. 2018, 44, 15402-15410. [CrossRef]

6. Roya, J.; Chandra, S.; Maitra, S. Nanotechnology in castable refractory. Ceram. Int. 2019, 45, 19-29. [CrossRef]

7. Matijevic, E. Uniform inorganic colloid dispersions. Achievements and challenges. Langmuir 1994, 10, 8-16. [CrossRef]

8. Michel, C.R.; Guillén-Bonilla, H.; Martínez-Preciado, A.H.; Morán-Lázaro, J.P. Synthesis and gas sensing properties of nanostructured $\mathrm{CoSb}_{2} \mathrm{O}_{6}$ microspheres. Sens. Actuators B Chem. 2009, 143, 278-285. [CrossRef]

9. Gao, X.; Zhang, T. An overview: Facet-dependent metal oxide semiconductor gas sensors. Sens. Actuators B Chem. 2018, 277, 604-633. [CrossRef]

10. Degler, D. Trends and Advances in the Characterization of Gas Sensing Materials Based on Semiconducting Oxides. Sensors 2018, 18, 3544. [CrossRef]

11. Fragoso-Mora, J.R.; Matatagui, D.; Bahos, F.A.; Fontecha, J.; Fernandez, M.J.; Santos, J.P.; Sayago, I.; Gràcia, I.; Horrillo, M.C. Gas sensors based on elasticity changes of nanoparticle layers. Sens. Actuators B Chem. 2018, 268, 93-99. [CrossRef] 
12. Yang, X.; Zhang, S.; Yu, Q.; Zhao, L.; Sun, P.; Wang, T.; Liu, F.; Yan, X.; Gao, Y.; Liang, X.; et al. One step synthesis of branched $\mathrm{SnO}_{2} / \mathrm{ZnO}$ heterostructures and their enhanced gas-sensing properties. Sens. Actuators B Chem. 2019, 281, 415-423. [CrossRef]

13. Ding, J.-C.; Li, H.-Y.; Cao, T.-C.; Cai, Z.-X.; Wang, X.-X.; Guo, X. Characteristics and sensing properties of CO gas sensors based on $\mathrm{LaCo}_{1-x} \mathrm{FexO}_{3}$ nanoparticles. Solid State Ion. 2017, 3030, 97-102.

14. Singh, S.; Singh, A.; Singh, A.; Tandon, P. A stable and highly sensitive room-temperature liquefied petroleum gas sensor based on nanocubes/cuboids of zinc antimonate. RSC Adv. 2020, 10, 20349-20357. [CrossRef]

15. Morán-Lázaro, J.P.; Blanco, O.; Rodríguez-Betancourtt, V.-M.; Reyes-Gómeze, J.; Michel, C.R. Enhanced $\mathrm{CO}_{2}$-sensing response of nanostructured cobalt aluminate synthesized using a microwave-assisted colloidal method. Sens. Actuators B Chem. 2016, 226, 518-524. [CrossRef]

16. Balamurugana, C.; Maheswari, A.R.; Lee, D.-W. Structural, optical, and selective ethanol sensing properties of p-type semiconducting $\mathrm{CoNb}_{2} \mathrm{O}_{6}$ nanopowder. Sens. Actuators B Chem. 2014, 205, 289-297. [CrossRef]

17. Cheng, B.; Ouyang, Z.; Tian, B.; Xiao, Y.; Lei, S. Porous $\mathrm{ZnAl}_{2} \mathrm{O}_{4}$ spinel nanorods: High sensitivity humidity sensors. Ceram. Int. 2013, 39, 7379-7386. [CrossRef]

18. Fernandez-Osorio, A.; Rivera, C.E.; Vazquez-Olmos, A.; Chavez, J. Luminescent ceramic nano-pigments based on terbium-doped zinc aluminate: Synthesis, properties and performance. Dyes Pigment. 2015, 119, 22-29. [CrossRef]

19. Wang, S.-F.; Tsai, Y.-T.; Chu, J.P. Resistive switching characteristics of a spinel $\mathrm{ZnAl}_{2} \mathrm{O}_{4}$ thin film prepared by radio frequency sputtering. Ceram. Int. 2016, 42, 17673-17679. [CrossRef]

20. Dhak, D.; Pramanik, P. Particle size comparison of soft-chemically prepared transition metal (Co, Ni, Cu, Zn) aluminate spinels. J. Am. Ceram. Soc. 2006, 89, 1014-1021. [CrossRef]

21. Ianoş, R.; Băbuţă, R.; Păcurariu, C.; Lazău, R.; Istratie, R.; Butaciu, C. Combustion synthesis of $\mathrm{ZnAl}_{2} \mathrm{O}_{4}$ powders with tuned surface area. Ceram. Int. 2017, 43, 8975-8981. [CrossRef]

22. Tangcharoen, T.; Thienprasert, J.-T.; Kongmark, C. Optical properties and versatile photocatalytic degradation ability of $\mathrm{MAl}_{2} \mathrm{O}_{4}$ $(\mathrm{M}=\mathrm{Ni}, \mathrm{Cu}, \mathrm{Zn})$ aluminate spinel nanoparticles. J. Mater. Sci. Mater. Electron. 2018, 29, 8995-9006. [CrossRef]

23. Cullity, B.D. Elements of X-ray Diffraction; Addison-Wesly Publishing Company, Inc.: Boston, MA, USA, 1956.

24. Ianos, R.; Borcanescu, S.; Lazau, R. Large surface area $\mathrm{ZnAl}_{2} \mathrm{O}_{4}$ powders prepared by a modified combustion technique. Chem. Eng. J. 2014, 240, 260-263. [CrossRef]

25. Muñoz-Flores, J.; Herrera-Gomez, A. Resolving overlapping peaks in ARXPS data: The effect of noise and fitting method. J. Electron Spectrosc. Relat. Phenom. 2012, 184, 533-541. [CrossRef]

26. Zhang, D.; Du, C.; Chen, J.; Shi, Q.; Wang, Q.; Li, S.; Wang, W.; Yan, X.; Fan, Q. Improvement of structural and optical properties of $\mathrm{ZnAl}_{2} \mathrm{O}_{4}: \mathrm{Cr}^{3+}$ ceramics with surface modification by using various concentrations of zinc acetate. J. Sol-Gel Sci. Technol. 2018, 88, 422-429. [CrossRef]

27. Cabello, G.; Lillo, L.; Caro, C.; Seguel, M.; Sandoval, C.; Buono-Core, G.E.; Chornik, B.; Flores, M. A photochemical proposal for the preparation of $\mathrm{ZnAl}_{2} \mathrm{O}_{4}$ and $\mathrm{MgAl}_{2} \mathrm{O}_{4}$ thin films from b-diketonate complex precursors. Mater. Res. Bull. 2016, 77, 212-220. [CrossRef]

28. Ceballos-Sanchez, O.; Sanchez-Martinez, A.; Vazquez-Lepe, M.O.; Duong, T.; Arroyave, R.; Espinosa-Magaña, F.; Herrera-Gómez, A. Mass transport and thermal stability of TiN/ $\mathrm{Al}_{2} \mathrm{O}_{3} / \mathrm{InGaAs}$ nanofilms. J. Appl. Phys. 2012, 112, 053527. [CrossRef]

29. Alfaro-Cruz, M.R.; Ceballos-Sanchez, O.; Luévano-Hipólito, E.; Torres-Martínez, L.M. ZnO thin films deposited by RF magnetron sputtering: Effects of the annealing and atmosphere conditions on the photocatalytic hydrogen production. Int. J. Hydrogen Energy 2018, 43, 10301-10310. [CrossRef]

30. Iaiche, S.; Djelloul, A. $\mathrm{ZnO} / \mathrm{ZnAl}_{2} \mathrm{O}_{4}$ Nanocomposite films studied by X-ray diffraction, FTIR, and X-ray photoelectron spectroscopy. J. Spectrosc. 2015, 2015, 836859. [CrossRef]

31. López, R.; Gómez, R. Band-gap energy estimation from diffuse reflectance measurements on sol-gel and commercial TiO 2 : A comparative study. J Sol-Gel Sci. Technol. 2012, 6, 1-7. [CrossRef]

32. Motloung, S.V.; Dejene, F.B.; Ntwaeaborwa, O.M.; Swart, H.C. Effects of catalyst/zinc mole fraction on $\mathrm{ZnAl}_{2} \mathrm{O}_{4}: 0.01 \% \mathrm{Cr}^{3+}$ nanocrystals synthesized using sol-gel process. Mater. Res. Express. 2014, 1, 045029. [CrossRef]

33. Dixit, H.; Tandon, N.; Cottenier, S.; Saniz, R.; Lamoen, D.; Partoens, B.; Speybroeck, V.V.; Waroquier, M. Electronic structure and band gap of zinc spinel oxides beyond LDA: $\mathrm{ZnAl}_{2} \mathrm{O}_{4}, \mathrm{ZnGa}_{2} \mathrm{O}_{4}$ and $\mathrm{ZnIn}_{2} \mathrm{O}_{4}$. New J. Phys. 2011, 13, 063002. [CrossRef]

34. Wang, X.; Li, Y. Solution-based synthetic strategies for 1-D nanostructures. Inorg. Chem. 2006, 45, 7522-7534. [CrossRef] [PubMed]

35. Deng, Z.-X.; Wang, C.; Sun, X.-M.; Li, Y.D. Structure-directing coordination template effect of ethylenediamine in formations of $\mathrm{ZnS}$ and $\mathrm{ZnSe}$ nanocrystallites via solvothermal route. Inorg. Chem. 2002, 41, 869-873. [CrossRef]

36. Guillen-Bonilla, H.; Olvera-Amador, M.L.; Casallas-Moreno, Y.L.; Guillen-Bonilla, J.T.; Guillen-Bonilla, A.; Gildo-Ortiz, L.; MoranLazaro, J.P.; Santoyo-Salazar, J.; Rodriguez-Betancourtt, V.-M. Synthesis and characterization of nickel antimonate nanoparticles: Sensing properties in propane and carbon monoxide. J. Mater. Sci. Mater. Electron. 2019, 30, 6166-6177. [CrossRef]

37. Guillen-Bonilla, J.T.; Guillen-Bonilla, H.; Rodríguez-Betancourtt, V.M.; Casillas-Zamora, A.; Ramírez-Ortega, J.A.; Gildo-Ortiz, L.; Sánchez-Morales, M.E.; Blanco-Alonso, O.; Guillén-Bonilla, A. Carbone monoxide (CO) detection device based on the nickel antimonate oxide and a DC electronic circuit. Appl. Sci. 2019, 9, 3799. [CrossRef]

38. Guillen-Bonilla, H.; Rodríguez-Betancourtt, V.M.; Guillen-Bonilla, J.T.; Gildo-Ortiz, L.; Guillén-Bonilla, A.; Casallas-Moreno, Y.L.; Blanco-Alonso, O.; Reyes-Gómez, J. Sensitivity tests of pellets made from manganese antimonate nanoparticles in carbon monoxide and propane atmospheres. Sensors 2018, 18, 2299. [CrossRef] 
39. Casillas-Zamora, A.; Guillen-Bonilla, J.T.; Guillén-Bonilla, A.; Rodríguez-Betancourtt, M.; Casallas-Moreno, Y.L.; Gildo-Ortiz, L.; Olvera-Amador, M.L.; Tomás, S.A.; Guillen-Bonilla, H. Synthesis of $\mathrm{MnSb}_{2} \mathrm{O}_{6}$ powders through a simple low-temperature method and their test as a gas sensor. J. Mater. Sci. Mater. Electron. 2020, 31, 7359-7372. [CrossRef]

40. Michel, C.R.; Martínez-Preciado, A.H.; Morán-Lázaro, J.P. Effect of the frequency on the gas sensing response of $\mathrm{CoSb}_{2} \mathrm{O}_{6}$ prepared by a colloidal method. Sens. Actuators B Chem. 2009, 140, 149-154. [CrossRef]

41. LaMer, V.K.; Dinegar, R.H. Theory, production and mechanism of formation of monodispersed hydrosols. J. Am. Chem. Soc. 1950, 72, 4847-4854. [CrossRef]

42. Wang, C.; Yin, L.; Zhang, L.; Xiang, D.; Gao, R. Metal oxide gas sensors: Sensitivity and influencing factors. Sensors 2010, 10, 2088-2106. [CrossRef] [PubMed]

43. Singh, S.; Singh, A.; Singh, A.; Rathore, S.; Yadav, B.C.; Tandon, P. Nanostructured cobalt antimonate: A fast responsive and highly stable sensing material for liquefied petroleum gas detection at room temperature. RSC Adv. 2020, 10, 33770-33781. [CrossRef]

44. Arshak, K.; Moore, E.; Lyons, G.M.; Harris, J.; Clifford, S. A review of gas sensors employed in electronic nose applications. Sens. Rev. 2004, 24, 181-198. [CrossRef]

45. Cavallari, M.R.; Pastrana, L.M.; Sosa, C.D.F.; Marquina, A.M.R.; Izquierdo, J.E.E.; Fonseca, F.J.; Amorim, C.A.d.; Paterno, L.G.; Kymissis, I. Organic thin-film transistors as gas sensors: A Review. Materials 2021, 14, 3. [CrossRef]

46. Chang, S.C. Oxygen chemisorption on tin oxide: Correlation between electrical conductivity and EPR measurements. J. Vac. Sci. Technol. 1979, 17, 366-369. [CrossRef]

47. Fioravanti, A.; Marani, P.; Morandi, S.; Lettieri, S.; Mazzocchi, M.; Sacerdoti, M.; Carotta, M.C. Growth Mechanisms of ZnO Micro-Nanomorphologies and Their Role in Enhancing Gas Sensing Properties. Sensors 2021, 21, 1331. [CrossRef]

48. Lin, T.; Lv, X.; Li, S.; Wang, Q. The morphologies of the semiconductor oxides and their gas-sensing properties. Sensors 2017, 17, 2779. [CrossRef]

49. Alrammouz, R.; Podlecki, J.; Abboud, P.; Sorli, B.; Habchi, R. A review on flexible gas sensors: From materials to devices. Sens. Actuators A Phys. 2018, 284, 209-231. [CrossRef]

50. Zhou, Q.; Chen, W.; Xu, L.; Kumar, R.; Gui, Y.; Zhao, Z.; Tang, C.; Zhu, S. Highly sensitive carbon monoxide (CO) gas sensors based on $\mathrm{Ni}$ and $\mathrm{Zn}$ doped $\mathrm{SnO}_{2}$ nanomaterials. Ceram. Int. 2018, 44, 4392-4399. [CrossRef]

51. Gómez-Pozos, H.; González-Vidal, J.L.; Torres, G.A.; Olvera, M.L.; Castañeda, L. Physical characterization and effect of effective surface area on the sensing properties of tin dioxide thin solid films in a propane atmosphere. Sensors 2013, 14, 403-415. [CrossRef]

52. Gómez, H.; González, J.L.; Torres, G.A.; Rodríguez, J.; Maldonado, A.; Olvera, M.L.; Acosta, D.R.; Avendaño, M.; Castañeda, L. Chromium and ruthenium-doped zinc oxide thin films for propane sensing applications. Sensors 2013, 13, 3432-3444. [CrossRef] [PubMed]

53. Guillén-Bonilla, H.; Rodríguez-Betancourtt, V.M.; Guillén Bonilla, J.T.; Reyes-Gómez, J.; Gildo-Ortiz, L.; Flores-Martínez, M.; Olvera-Amador, M.L.; Santoyo-Salazar, J. $\mathrm{CO}$ and $\mathrm{C}_{3} \mathrm{H}_{8}$ sensitivity behavior of zinc antimonate prepared by a microwaveassisted solution method. J. Nanomater. 2015, 2015, 979543. [CrossRef]

54. Guillén-Bonilla, H.; Gildo-Ortiz, V.; Olvera-Amador, M.L.; Santoyo-Salazar, J.; Rodríguez-Betancourtt, V.M.; Guillén-Bonilla, A.; Reyes-Gómez, J. Sensitivity of mesoporous $\mathrm{CoSb}_{2} \mathrm{O}_{6}$ nanoparticles to gaseous $\mathrm{CO}$ and $\mathrm{C}_{3} \mathrm{H}_{8}$ at low temperatures. J. Nanomater. 2015, 2015, 308465. [CrossRef] 